\title{
Analysis of transverse vibration and stability issues of discrete-continuous elastic systems with nonlinearly variable parameters
}

\author{
Jerzy Jaroszewicz ${ }^{1, *}$, Eukasz Dragun ${ }^{1}$ \\ ${ }^{1}$ Bialystok University of Technology, Faculty of Engineering Management, Ojca Tarasiuka 2, 16-001 \\ Kleosin, Poland
}

\begin{abstract}
The work is devoted to methods of analysis of vibrations and stability of discrete-continuous, multi-parameter models of beams, shafts, rotors, vanes, converting to homogeneous and one-dimensional. The properties of Cauchy's influence function and the characteristic series method were used to solve the boundary problem. It has been shown that the methods are an effective tool for solving boundary problems described by ordinary fourth- and second-order differential equations with variable parameters. Particular attention should be paid to the solution of the border problem of two-parameter elastic systems with variable distribution of parameters. Universal beam-specific equations with typical support conditions including vertical support, which do not depend on beam shape and axial load type, are recorded. The shape and type of load are considered in the form of an impact function that corresponds to any change in cross-section of the support and continuous axial load, so that the functions describing the stiffness, the mass and the continuous load are complete. As a result of the solution of the boundary vibration problem of freely bent support and any change in its cross-section, loaded with any longitudinal load, arranged on the resilient substrate, strict relations between the own frequency parameters and the load parameters were derived. Using the methods, simple calculations were made, easy to use in engineering practice and conditions of use were given. Experimental studies have confirmed the high accuracy of theoretical calculations using the proposed methods and formulas.
\end{abstract}

Keywords: beams, boundary issues, transverse oscillations, intrinsic frequency stability, critical loads

\section{Introduction}

Components such as turbine blades, helicopter carrier blades, engine rotors, machine spindles, crane booms, drilling rigs, masts can be modeled with beams of variable distribution of parameters, the most important of which are: rigidity, mass, modulus of elasticity, cross section, substrate elasticity Longitudinal load. Sometimes discrete inclusions in the distribution of mass and in the resilient substrate should also be considered. We need to know the relevant dynamic characteristics, such as: values and

\footnotetext{
${ }^{*}$ Corresponding author: j.jaroszewicz@pb.edu.pl

Reviewers: Maciej Bodnicki, Robert Zalewski
} 
forms of our own vibrations, and critical loads, in the loss of stability of the divergence and flatter type [1-3].

The exact solution of the abovementioned, in the general case, is possible in only a few specific cases. In the paper [4], the boundary of vibration of the cantilevered cone with the Bessel function is solved. The output equation of the vibration of flexible beams with a power-varying cross-section may be in the form of the Euler equation and then the general integral is expressed by the elementary functions [5-7].

The analytical and above all numerical methods used to test such beams are [8-10]. Using this method, it is quite difficult to assess the accuracy of the calculation of the required characteristics.

Among the numerical methods, finite element method and finite difference method are widely used [11, 12]. Examples of analytical methods are variation methods that, although they do not guarantee high accuracy; because of the specific form of vibrations, they give a very simple form of solution [10]. It is impossible not to mention the method of subsequent approximations. On the basis of this, Mike has derived the characteristic equation of the cantilever beam with varying cross section, but it has a very complicated form [5].

It is noted that there are no works that take into account several variable parameters at the same time, therefore the proposal of Zoryj L.M. and Jaroszewicz J. to apply for this purpose the method of characteristic series. This proposal was developed in joint work [27]. It must be clarified that Bernstein's previously proposed "spectral function" method was used only to analyze systems with fixed parameters without considering friction $[10,13]$. At work [6] Zoryj L.M. He gave the general way of building universal determinants in the case of multi-parameter springs. The proposed method was then applied to the typical boundary problems described by the second and fourth order ordinary differential equations. The authors of this work $[10,11]$ have used a series of characteristic methods to solve the boundary free-floating edge problem of a cantilever beam with a freely varying cross section. General formulas have been obtained which characterize the characteristic coefficients used in [5] for vibration analysis of cantilever beam of different shapes. Work [5] has also derived models that can be applied in engineering practice to calculate the basic vibration frequencies of the flexible beams and their conditions of use. The authors practically use the important property of the Cauchy function, published by L. Zoryj in 1978, which indicates that the function of influence and its subsequent derivative with respect to the parameter always form the basic arrangement of ordinary differential equation with variable parameters.

In this chapter, the boundary problem of the resilient spring flexing support beams has been formulated: flexural stiffness, continuous mass, longitudinal load, resilient substrate, which also contains discrete inclusions such as concentrated masses, resilient supports.

The replacement model of the beam in question is shown in Figure 1, on which it is marked: $f(x)$ - Rigid stiffness; $\mu(x)$ - continuous mases distribution; $k(x)$ - stiffness of the elastic substrate; $p(x)$ - longitudinal loads; $b(x)$ - external friction; $\mathrm{N}(\mathrm{x})$ - denotes distributed axial loads; $M_{i}, b_{i}, c_{i}$ - discrete inclusions in continuous mass distribution, in the external friction and in the resilient substrate, applied in points $x_{i} ; l$-beam length; $x, w$ - co-ordinates. As a result, the general form of the characteristic equation was obtained, on the basis of which it is possible to calculate the estimate of the frequencies of the own vibration and the estimates of the critical forces. Several typical examples, often found in engineering practice, were considered. 


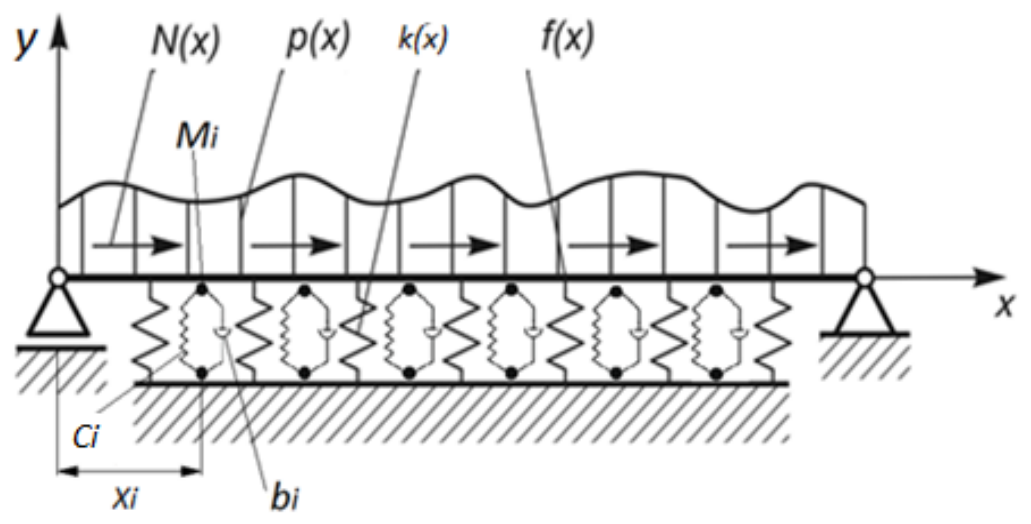

Fig. 1. The beam model

In particularly cases flexural rigidity and continuous mases may have form likes: $\mathrm{f}(\mathrm{x})=$ $\mathrm{EJ}_{0}\left(1-\gamma \frac{x}{l}\right)^{n}$ and $\mathrm{M}(\mathrm{x})=\mu_{0}\left(1-\gamma \frac{x}{l}\right)^{\frac{n}{2}}, \gamma-$ coefficient of conquers; $\mathrm{J}_{0}$ - moment of inertia and mases of section $\mathrm{x}=0$.

\section{Definition of the problem}

Vibrations of bent rods of length $l$ that occur in the plane $\mathrm{O}_{\mathrm{yx}}$, can be described using the equation $[4,5]$ :

$$
\frac{\partial^{2}}{\partial x^{2}}\left(f \frac{\partial^{2} y}{\partial x^{2}}\right)-\frac{\partial}{\partial x}\left(N \frac{\partial y}{\partial x}\right)+\varrho F \frac{\partial^{2} y}{\partial t^{2}}+b \frac{\partial y}{\partial t}+c y=q(x, t)
$$

Where the signs are in accordance with Figure 1 and the previous description.

Equation (1) is considered under typical boundary conditions, two at each end of the bar and specified initial conditions (2). We will consider tasks of free vibration under typical boundary conditions, in the absence of external constraint, where $q(x, t) \equiv 0$. Separating variables $(x, t)$ we come to the equation:

$$
\left(f y^{\prime \prime}\right)^{\prime \prime}-\left(N f^{\prime}\right)^{\prime}+\left(\varrho F \lambda^{2}+b \lambda+c\right) y=0
$$

The following boundary conditions are considered:

$$
\begin{gathered}
y(0)=0, \quad y^{\prime}(0)=0 ; \quad y(l)=0, y^{\prime}(l)=0 \\
y(0)=0, y^{\prime}(0)=0 ; \quad y(l)=0,\left.f y^{\prime \prime}\right|_{x=l}=0 \\
y(0)=0, y^{\prime \prime}(0)=0 ; \quad y(l)=0, y^{\prime \prime}(l)=0 \\
y(0)=0, \quad y^{\prime}(0)=0 ; \quad y(1)=0,\left.\left(\mathrm{f} y+N y^{\prime}\right)\right|_{x=l}=0
\end{gathered}
$$


By substituting the general form of the solution for the above bounded boundary conditions $(3,4,5,6)$ we obtain the following characteristic equations [9]:

1) For a bar with two fixed ends the problem (2), (3):

$$
F(l, 0)=0
$$

2) For a bar with a left-right and a right freely supported issue (2), (4):

$$
F^{\prime}(l, 0)=0
$$

3) For a bar with two articulated-based issues (2), (5) clamped:

$$
S^{\prime}(l, 0)=0
$$

4) For the bracket issue (2), (6) supported cantilever:

$$
R(l, 0)=0
$$

In the above equations, Cauchy's derivatives of their derivatives are used [10]:

$$
\begin{gathered}
F(x, \alpha) \equiv \phi \dot{\phi}^{\prime}-\dot{\phi} \phi^{\prime} \\
S^{\prime}(x, \alpha) \equiv \phi \ddot{\phi^{\prime \prime}}-\ddot{\phi} \phi^{\prime \prime} \\
R(x, \alpha) \equiv f(x)\left(\phi^{\prime \prime} \dot{\phi}^{\prime \prime \prime}-\phi^{\prime \prime \prime} \dot{\phi}^{\prime \prime}\right)+N(x)\left(\phi^{\prime} \dot{\phi^{\prime \prime}}-\phi^{\prime \prime} \dot{\phi}^{\prime \prime}\right)
\end{gathered}
$$

where: $\phi(\mathrm{x}, \alpha)$ - fundamental solution of the equation (2), Dots "." Denote derivatives with respect to $\alpha$ ', "," denote derivatives with respect to $\mathrm{x}$.

We will now assume, as in the case of the string vibration task, that there is interdependence [5]. Then in place of (2) the equation [5] should be considered:

$$
\left(f y^{\prime \prime}\right)^{\prime \prime}-(N y)^{\prime}-\sum_{i=1}^{v} \alpha_{i} y\left(x_{i}\right) \varrho\left(x-x_{i}\right)=0
$$

where

$$
-\alpha_{i}=M_{i} \lambda^{2}+b_{i} \lambda+c_{i}
$$

$\mathrm{M}_{\mathrm{i}}$-size of concentrated mass,

$b_{i}, c_{i}$ - coefficients of friction and stiffness of the spring at the coordinate $x_{i .}$,

In this case, the boundary conditions (3-6) correspond to the characteristic equations (710 ) corresponding to the given case, that is, the equation (14) of the functions $F, S$, and $R$ obtained from (11), (12), (13) By replacement instead $\phi(\mathrm{x}, \alpha)$ solutions $Q_{1}(x, \alpha)=\phi_{x \alpha}+$ $\alpha_{1} \phi_{1 \alpha} \phi_{x 1}$, determined by dependency (1.29 saved in [5]), wherein $\psi_{\mathrm{s}}(\mathrm{x})$ is the fundamental solution of the equation:

$$
\left(f y^{\prime \prime}\right)^{\prime \prime}-\left(N y^{\prime}\right)^{\prime}=0
$$

\section{Examples of survey requirements with no quantity will come freedoms}

We will examine some simple examples. Let $Y_{v}=1, N(x) \equiv 0$. Then based on the formula (1.29 saved in [5]) we get: 


$$
Q_{1}(x, \alpha)=\phi_{x \alpha}+\alpha_{1} \phi_{1 \alpha} \phi_{x 1}
$$

where:

$$
\phi(x, \alpha)=\int_{\alpha}^{x} \frac{1}{f(s)}(x-s)(s-\alpha) d s * \theta(x-\alpha)
$$

Substitute (17) for the characteristic equation (11), which corresponds to the beam with two fixed ends, from which, after some transformations, we obtain:

$$
\alpha_{1}=V(l, 0)\left[V\left(x_{1,0}\right) \int_{x_{1}}^{l} \frac{\left(t-x_{1}\right)^{2}}{f(x)} d t+v(l, x) \int_{0}^{x_{1}} \frac{\left(t-x_{1}\right)^{2}}{f(t)} d t\right]^{-1}
$$

where:

$$
V(x, \alpha) \equiv \int_{\alpha}^{x} \frac{d t}{f(t)} \int_{\alpha}^{x} \frac{t^{2} d t}{f(t)}-\left(\int_{\alpha}^{x} \frac{t d t}{f(t)}\right)^{2}
$$

Based on equations (8) and (9) considering (17 - 20) we find:

$$
\alpha_{1}=V^{\prime}(l, 0)\left[V\left(x_{1}, 0\right) \frac{\left(l-x_{1}\right)}{f(l)}+V^{\prime}\left(l, x_{1}\right) \int_{0}^{x_{1}} \frac{\left(t-x_{1}\right)^{2}}{f(t)} d t\right]^{-1}
$$

and finally:

$$
\alpha_{1}=l^{2}\left[\left(l-x_{1}\right)^{2} \int_{0}^{x_{1}} \frac{t^{2}}{f(t)} d t+x_{1}^{2} \int_{x_{1}}^{l} \frac{(l-t)^{2}}{f(t)} d t\right]^{-1}
$$

Using (17) and proceeding analogously to the above, we obtain the following pattern for the bracket, which carries the resiliently attached mass at the end of the equation (10) $/ \mathrm{x}_{1}=\mathrm{l} /$ :

$$
\alpha_{1}=\left[\int_{0}^{l} \frac{(l-s)^{2}}{f(s)} d s\right]^{-1}
$$

Dependencies (19) and (21 - 23) which represent the square equations with respect to the characteristic index $\lambda$, allows you to specify frequencies / complex / extinguishing vibrations corresponding to systems with one degree of freedom for any given flexural stiffness $\mathrm{f}(\mathrm{x})>0 / 0<\mathrm{x}<\mathrm{l} /$ and coefficient of friction $\mathrm{b}_{1}>0$, satisfactory condition of continuation of vibration. We will note that in the case $\mathrm{f}(\mathrm{x})=0=\mathrm{EJ}_{0}=$ const., $\mathrm{b}_{1}=\mathrm{c}_{1}=0$, Based on these relationships it is easy to come up with patterns known from the literature for the squares of the frequencies of the corresponding vibrations, the bars in question, and also for the critical speeds of the shafts with the disk.

If instead of a concentrated mass $\tilde{\mu}$ at the point $\xi$ there is a spring attached to the mass bar $\mu$ on spring with stiffness $\tilde{c}$ and damper with friction coefficient $\tilde{\varepsilon}$, is a parameter $\alpha_{i}$ instead (15) should be specified in the form:

$$
\widetilde{-\alpha_{l}}=\widetilde{M}_{l} \lambda^{2}\left(\widetilde{\varepsilon_{l}} \lambda+\widetilde{c_{l}}\right)\left(\widetilde{M_{l}} \lambda^{2}+\widetilde{\varepsilon_{l}} \lambda+\widetilde{c_{l}}\right)^{-1}
$$

In the case of the presence at the point xi of both masses / rod and rod spring / add the total parameter $-\widehat{\alpha_{\imath}+\alpha_{\imath}}$.

For example, for a support that carries a fixed mass $\mathrm{M}$ on its end with an elastic support with a stiffness $\mathrm{c}$ and a coefficient of friction $\mathrm{b}$ and an additional spring loaded mass $\tilde{M}$, with stiffness of spring $\mathrm{c}$ with wavelength and coefficient of friction $\tilde{\varepsilon}$, based on (23) we obtain the following equation: 


$$
M \lambda^{2}+b \lambda+c+\widetilde{M} \lambda^{2} \frac{\tilde{\varepsilon} \lambda+\tilde{c}}{\widetilde{M} \lambda^{2}+\tilde{\varepsilon} \lambda+\tilde{c}}+\left(\int_{0}^{l} \frac{(l-s)^{2}}{f(s)} d s\right)^{-1}=0
$$

Hence, it is possible to determine the frequency of a series of corresponding systems with two degrees of freedom, and in particular we come to comply with the solutions known from the literature of tasks.

As a next example we will consider the task of free vibration without a mass beam with freely supported ends bearing the masses at the axes $\mathrm{x}_{\mathrm{i}}=1,2,3$ And with elastic support bars at these points. General solution of the equation (14) if the longitudinal force does not work $\mathrm{N}(\mathrm{x}) \equiv 0$ has character (1.31 saved in [5]); equations $\mathrm{Q}_{3 \mathrm{~s}}(\mathrm{~s})$ for $\mathrm{s}=1,4$ they are referred to as the pattern accordingly (1.29 saved in [5]) under the following conditions:

$$
\psi_{1}=1, \psi_{2}=x, \psi_{3}=\phi, \psi_{4}=\phi
$$

where:

Function $\phi(\mathrm{x}, \alpha)$ is defined by the integral (18). Assuming a parameter $\alpha$ equal 0 substituting (1.31 saved in [5]) to the conditions at the left end y" $(0)=0, y " \prime(0)=0$, we find out that $\mathrm{A}_{3}=0$ i $\mathrm{A}_{4}=0$.

Limit conditions at the right end give a linear system of homogeneous algebraic equations with respect to constants $\mathrm{A}_{1}, \mathrm{~A}_{2}$. We obtain the characteristic equation in the following form:

$$
\left|\begin{array}{ll}
Q^{\prime \prime}{ }_{31} & Q^{\prime \prime}{ }_{32} \\
Q^{\prime \prime \prime}{ }_{31} & Q^{\prime \prime \prime}{ }_{32}
\end{array}\right|^{x=l} \begin{aligned}
& x=0 \\
& \alpha=0
\end{aligned}=0
$$

Note that at $\mathrm{x}_{1}=0$ calculations are much simpler, we assume that $\mathrm{x}_{1}=0$ and after doing some transformations from (27) we get:

$$
\begin{array}{r}
\alpha_{1} \alpha_{2} x_{2}^{2}+\alpha_{1} \alpha_{3} x_{3}^{2}+\alpha_{2} \alpha_{3}\left(x_{3}-x_{2}\right)^{2}+ \\
+\alpha_{1} \alpha_{2} \alpha_{3}\left\{x_{2}\left[\left(x_{2}-x_{3}\right) \phi_{31}+x_{3} \phi_{32}\right]+x_{3} \phi_{21}\left(x_{3}-x_{2}\right)\right\}=0
\end{array}
$$

where:

$$
\phi_{i j}=\int_{x_{i}}^{x_{j}} \frac{1}{f(s)}\left(x_{i}-s\right)\left(s-x_{j}\right) d s
$$

Based on the above equation (28), it is possible to determine the characteristic indices, i.e., the customary frequencies of a plurality of suitable three, two, one degrees of freedom, critical shaft speed with a disk, and also with respect to (24) and exemplary (25) discrete Number of degrees of freedom / up to six [11]/. Let, for example, $\alpha_{1}=\alpha_{2}=\infty$, instead of (28) we obtain the following equation:

$$
x_{2}^{2}+\alpha_{3}\left\{x_{2}\left[\left(x_{2}-x_{3}\right) \phi_{31}+x_{3} \phi_{32}\right]+x_{3} \phi_{21}\left(x_{3}-x_{2}\right)\right\}=0
$$

For $\mathrm{x}_{2}=\mathrm{l}-\mathrm{a}, \mathrm{x}_{3}=1, \mathrm{f}=\mathrm{EJ} \mathrm{J}_{0}=$ const., $\alpha_{3}=\mathrm{M} \omega^{2}$ we have respectively: $\phi_{21}=1 / 6_{\mathrm{l}-\mathrm{a}} 3_{\mathrm{f}-1}, \phi_{31}=\mathrm{l}_{3} / 6_{\mathrm{f}}$, $\phi_{32}=\mathrm{a}_{3} / 6_{\mathrm{f}}$ and based on (30) we determine the critical speed of the light shaft with discs occurring at the free end:

$$
\omega_{k p}^{2}=\frac{3 f}{a^{2} l}
$$


Based on (28), it is also possible to obtain, in specific cases, the question of the conditions under which the elastic supports are permissible to replace rigid, rigid stiffness which for non-homogeneous sections of the beam can be assumed to be large.

Let's, for example $\alpha_{1}=\alpha_{3}=-\mathrm{c}, \alpha_{2}=-\mathrm{M} \lambda_{2}$. With this equation (28) for the beam with constant stiffness, we obtain the following pattern for a small beam of length 1 with elastic supports at the ends, which carries the mass $\mathrm{M}$ at the point $\mathrm{x}_{2}=\frac{1}{2}$ :

$$
\omega^{2}=\frac{2 x}{M}\left(1+\frac{1}{24} c l^{3} / E J\right)^{-1}
$$

The above pattern (32) agrees with the solution of a known task [10]. Of course, at $1 / 24 \mathrm{cl}_{3} / \mathrm{EJ}<<1$ the beam can be considered absolutely rigid.

If, for example, the stiffness of the beam section between the points of its axis $x_{2}$ i $x_{3}$ Far outstrips stiffness between points $\mathrm{x}_{1} \mathrm{i} \mathrm{x}_{2}$, it's in the equation (28) should be assumed $\phi_{32}=0, \phi_{31}=\phi_{21}$, If the beam can be rigid, then in this expression in cubes is equal to zero. In the latter case, it is also possible to consider the left end freely supported if it is directed $\alpha 1$ to infinity. In this equation (28) looks:

$$
\alpha_{2} x_{2}^{2}+\alpha_{3} x_{3}^{2}=0
$$

Hence it is easy to come to a range of tasks with rigid rods with masses and resilient supports.

Table 1. Results of calculations of lower $\underline{a \omega_{0}}{ }^{2}$ and upper $\underline{a \omega_{0}}{ }^{2}$ estimators of base frequency for square cone $\mathrm{C}_{\mathrm{n}}=3$

\begin{tabular}{|c|c|c|c|c|c|c|c|}
\hline \multirow{2}{*}{ No. } & \multirow{2}{*}{$\boldsymbol{\gamma}$} & \multicolumn{2}{|c|}{ Analytical } & \multicolumn{2}{c|}{ Numerical } & \multirow{2}{*}{$\boldsymbol{\varepsilon}[\boldsymbol{\%}]$} & \multirow{2}{*}{ Experiment } \\
\cline { 3 - 6 } & & $\underline{\boldsymbol{a} \boldsymbol{\omega}_{0}{ }^{2}}$ & $\underline{\boldsymbol{\omega}_{0}{ }^{\mathbf{2}}}$ & $\underline{\boldsymbol{a} \boldsymbol{\omega}_{0}{ }^{\mathbf{2}}}$ & $\underline{\boldsymbol{a} \boldsymbol{\omega}_{0}{ }^{\mathbf{2}}}$ & & \\
\hline 1 & 2 & 3 & 4 & 5 & 6 & 7 & 8 \\
\hline 1 & 0 & 12.36 & 12.36 & 12.36 & 12.36 & 0.02 & - \\
2 & 0.2 & 13.01 & 13.02 & 13.01 & 13.02 & 0 & 14.02 \\
3 & 0.4 & 13.96 & 13.97 & 13.96 & 13.97 & 0 & - \\
4 & 0.6 & 15.46 & 15.49 & 15.46 & 15.49 & 0 & 14.43 \\
5 & 0.8 & 18.37 & 18.46 & 18.37 & 18.46 & 0 & - \\
6 & 1.0 & 28.03 & 28.52 & 29.94 & 31.29 & 7.66 & 32.03 \\
\hline
\end{tabular}

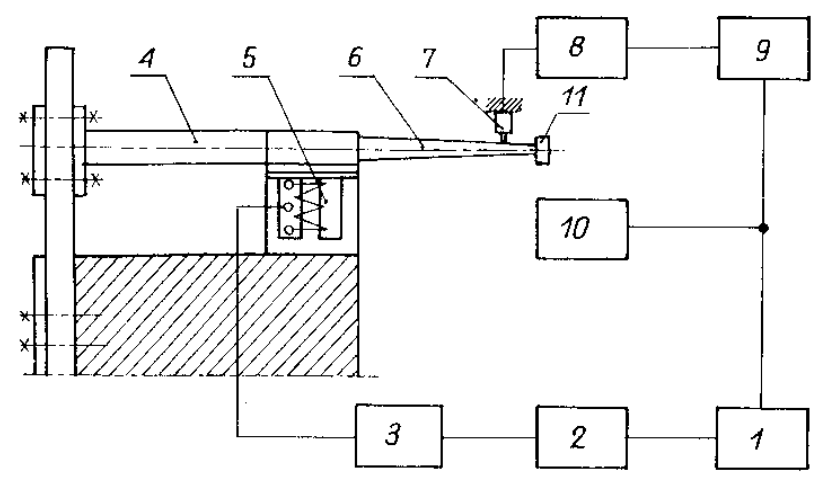

Fig. 2. Schematic diagram of the test stand by resonance method of flexural vibrations of cone with masses on end 
Oscilloscope 8, oscilloscope 9 and pulse 10 are used to measure the vibration frequencies of the sample, which is realized by means of a sensor 7 , oscilloscope 8 , oscilloscope 9, and pulse counter 10. When equalizing the vibration force of the oscilloscope 9, When moving through the resonance, the ellipse is overturned. The LC 3 resonator circuit is necessary because of the insufficient power of the amplifier 2 . The source of vibrations is electromagnet 5 supplied with variable frequency current, 1 generator, 2 - power amplifier, 3 LC resonant system. The electromagnet 5 excites the flexural vibrations of the sample 6, rigidly fixed at the end of the support 4 .

\section{Conclusion}

The proposed general expressions allow to obtain closed formulas for the second and third coefficients of a series characteristic for any function of stiffness from which it is required to be complete and have a finite value in the interval $(0,1)$.

The presented methods (analytical and numerical) for the calculation of coefficients of a series of characteristics, based on general patterns, provide high accuracy in all cases considered (Table 1). It can be expected that equally high accuracy of calculations will be obtained for beam with focus on the end of other transverse cross sectional variations. Only cases in which the stiffness function at the free end tends to zero requires calculating the limit values of the series coefficients.

In the case of beams and shafts, even a relatively small mass at the ends of the beams, significantly lowers the base frequency. Coefficient of convergence $\gamma$ this increases the frequency of beams without mass or very low mass $(\mu \leq 0,001)$. Section coefficients $n$ i $m$ they show a significant effect on the baseline rate only at $\mu=0$ and close to zero.

\section{References}

1. R. Panuszka, T. Uhl, Wyznaczenie częstości rezonansowych ciag-łych układów mechanicznych na przyktadzie belki $i$ plyty drgajacej. Archiwum Budowy Maszyn, Tom XXX 1-2, 111-123 (1983)

2. J. Jaroszewicz, L. M. Zoryj, Drgania giętne belki wspornikowej o zmiennym przekroju. Rozprawy Inżynierskie 33 (4), 537-547 (1985)

3. J. H. Lau, Vibration freqencies of tapered bars with end mass. Journal of Applied Mechanics 51, 179-181 (1984)

4. J. Jaroszewicz, L. M. Zoryj, Izgibnyje kolebanija i dinamičeskaja ustojčivost' balok s peremennymi parametrami. Prikladnaja mechanika, Kijev 30 (9), 75-81 (1994b)

5. J. Jaroszewicz, L. M. Zoryji, Metody analizy drgań $i$ statecznoxci kontynualnodyskretnych układów mechanicznych. Rozprawy Naukowe Politechniki Białostockiej 54, Białystok, 126 (1997)

6. L. M. Zoryj, Ob universalnych charakteristiceskich uravenijach v zadacach kolebanij $i$ ustojcivosti uprugich sistem. Mechanika Tverdogo Tiela 6, 155-162 (1982)

7. L. M. Zoryj, $K$ teorii ustojcivosti sistem s raspredelonnymi parametrami. Dokl. AN USSR 11A, 992-995 (1986)

8. J. Jaroszewicz, K.K. Żur, Ł. Dragun, The influence function in analysis of bending curve and reactions of elastic supports of beam with variable parameters. Journal of Theoretical and Applied Mechanics 52 (1), 247-255 (2014) 
9. J. Jaroszewicz, L. M. Zoryj, Investigation of the effect of axial loads on the transverse vibrations of a vertical cantilever with variable parameters. Prikladnaja Mechanika, International Applied Mechanics 36 (9), 129-137 (2000)

10. J. Jaroszewicz, Ł. Dragun, Limitation of Cauchy function method in analysis for double estimators of free transversal vibration of cantilever tapered shafts. Technical Sciences 16 (2), 131-142 (2013)

11. J. Jaroszewicz, L. Radziszewski, Ł. Dragun, The Study of the Effect of Static Axial Loads on Vertically-Mounted Tapered Cantilever Transverse Vibrations Using the Cauchy Function. Applied Mechanics and Materials 712, 49-54 (2015)

12. W. Antoniuk, J. Jaroszewicz, L. Radziszewski, Ł. Dragun, Theoretical stress analysisbased improvement of friction clutch disc manufacturing process. Czasopismo Techniczne. Mechanika, Politechnika Krakowska 113 (4-M), 73-79 (2016)

13. T. Hoang, D. Duhamel, G. Foret, H.P. Yin, P. Joyezb, R. Caby, Calculation of force distribution for a periodically supported beam subjected to moving loads. Journal of Soundand Vibration 388, 327-338 (2017) 